\title{
Identification and Structure-Function Study of Positive Allosteric Modulators of Kainate Receptors
}

\author{
Anja Probst Larsen, Sabine Fièvre, Karla Frydenvang, Pierre Francotte, Bernard Pirotte, \\ Jette Sandholm Kastrup, and Christophe Mulle
}

Biostructural Research, Department of Drug Design and Pharmacology, Faculty of Health and Medical Sciences, University of Copenhagen, Copenhagen, Denmark (A.P.L., K.F., J.S.K.); Interdisciplinary Institute for Neuroscience, University of Bordeaux, Centre National de la Recherche Scientifique, Unité Mixte de Recherche 5297, Bordeaux, France (A.P.L., S.F., C.M.); and Department of Medicinal Chemistry, Center for Interdisciplinary Research on Medicines, University of Liège, Liège, Belgium (P.F., B.P.)

Received November 30, 2016; accepted March 28, 2017

\begin{abstract}
Kainate receptors (KARs) consist of a class of ionotropic glutamate receptors, which exert diverse pre- and postsynaptic functions through complex signaling regulating the activity of neural circuits. Whereas numerous small-molecule positive allosteric modulators of the ligand-binding domain of $(S)-2-$ amino-3-(3-hydroxy-5-methylisoxazol-4-yl)propanoic acid (AMPA) receptors have been reported, no such ligands are available for KARs. In this study, we investigated the ability of three benzothiadiazine-based modulators to potentiate glutamate-evoked currents at recombinantly expressed KARs. 4-cyclopropyl-7-fluoro-3,4-dihydro-2H-1,2,4-benzothiadiazine 1,1dioxide (BPAM344) potentiated glutamate-evoked currents of GluK2a 21-fold at the highest concentration tested (200 $\mu \mathrm{M})$, with an $\mathrm{EC}_{50}$ of $79 \mu \mathrm{M}$. BPAM344 markedly decreased desensitization kinetics (from 5.5 to $775 \mathrm{~ms}$ ), whereas it only had a minor effect on deactivation kinetics. 4-cyclopropyl-7-hydroxy-3,4-dihydro- $2 \mathrm{H}$ -
\end{abstract}

1,2,4-benzothiadiazine 1,1-dioxide (BPAM521) potentiated the recorded peak current amplitude of GluK2a 12-fold at a concentration of $300 \mu \mathrm{M}$ with an $\mathrm{EC}_{50}$ value of $159 \mu \mathrm{M}$, whereas no potentiation of the glutamate-evoked response was observed for 7-chloro-4-(2-fluoroethyl)-3,4-dihydro-2H-1,2,4-benzothiadiazine 1,1-dioxide (BPAM121) at the highest concentration of modulator tested $(300 \mu \mathrm{M})$. BPAM344 $(100 \mu \mathrm{M})$ also potentiated the peak current amplitude of KAR subunits GluK3a (59-fold), GluK2a (15fold), GluK1b (5-fold), as well as the AMPA receptor subunit GluA1 ${ }_{i}$ (5-fold). X-ray structures of the three modulators in the GluK1 ligand-binding domain were determined, locating two modulatorbinding sites at the GluK1 dimer interface. In conclusion, this study may enable the design of new positive allosteric modulators selective for KARs, which will be of great interest for further investigation of the function of KARs in vivo and may prove useful for pharmacologically controlling the activity of neuronal networks.

\section{Introduction}

Kainate receptors (KARs) are ionotropic glutamate receptors (iGluRs) composed of tetrameric assemblies of the GluK1-5 subunits (Pinheiro and Mulle, 2006; Lerma and Marques, 2013). Each subunit consists of the extracellular N-terminal domain (NTD), a ligand-binding domain (LBD), a helical transmembrane domain (TMD), and an intracellular, highly flexible C-terminal domain. The TMDs show 4-fold symmetry, whereas the LBDs and NTDs show 2-fold symmetry and are arranged as dimerof-dimers (Sobolevsky et al., 2009). Each LBD contains two subdomains, D1 and D2, forming a clamshell-like structure with the agonist-binding site located between D1 and D2, and two

This work was supported by the Centre National de la Recherche Scientifique of France (S.F., C.M.), the Fondation pour la Recherche Médicale (S.F.), the Lundbeck Foundation (A.P.L., K.F., J.S.K.), GluTarget (A.P.L., K.F., J.S.K.), and Danscatt (A.P.L., K.F., J.S.K.).

https://doi.org/10.1124/mol.116.107599. adjacent D1 domains forming the LBD dimer interface. Upon agonist binding, D2 moves toward D1, transferring a conformational strain to the TMD, which promotes channel opening. The receptor can undergo either desensitization (disruption of the D1-D1 interface with glutamate still bound) or deactivation (unbinding of glutamate), which leads to channel closure (Armstrong and Gouaux, 2000; Sobolevsky et al., 2009).

Although postsynaptic $N$-methyl-D-aspartic acid and $(S)-2$ amino-3-(3-hydroxy-5-methylisoxazol-4-yl)propanoic acid (AMPA) receptors (AMPARs) mediate most of the basal excitatory synaptic transmission, KARs display more diverse functions that rely on a variety of subcellular localization and signaling mechanisms to regulate the activity of neural circuits. Progress in understanding the physiologic functions and pharmacology of KARs at a cellular as well as at whole brain levels has lagged behind the other iGluRs due, in part, to a lack of selective pharmacological agents (Jane et al., 2009). Subunit selective agonists and antagonists for KARs that

ABBREVIATIONS: AMPA, (S)-2-amino-3-(3-hydroxy-5-methylisoxazol-4-yl)propanoic acid; AMPAR, AMPA receptor; BPAM97, 4-ethyl-7-fluoro3,4-dihydro-2H-1,2,4-benzothiadiazine 1,1-dioxide; BPAM121, 7-chloro-4-(2-fluoroethyl)-3,4-dihydro-2 $\mathrm{H}$-1,2,4-benzothiadiazine 1,1-dioxide; BPAM344, 4-cyclopropyl-7-fluoro-3,4-dihydro-2H-1,2,4-benzothiadiazine 1,1-dioxide; BPAM521, 4-cyclopropyl-7-hydroxy-3,4-dihydro-2H-1,2,4benzothiadiazine 1,1-dioxide; BTD, 1,2,4-benzothiadiazine 1,1-dioxide; IDRA21, 7-chloro-3-methyl-3,4-dihydro-2H-1,2,4-benzothiadiazine 1,1-dioxide; iGluR, ionotropic glutamate receptor; KAR, kainate receptor; LBD, ligand-binding domain; NTD, N-terminal domain; PEG4000, polyethylene glycol 4000; TMD, transmembrane domain; vdW, van der Waals. 
contain GluK1 subunits have been developed, whereas no selective ligands for the other KAR subunits have been identified despite intense efforts (Jane et al., 2009).

Multiple allosteric-binding sites for small-molecule positive and negative modulators, ions, and polyamines as well as toxins have been identified in the NTD, LBD, and TMD of iGluRs (Zhu and Gouaux, 2017). The AMPAR LBD dimer interface harbors a binding site for several classes of positive allosteric modulators (Pøhlsgaard et al., 2011), such as cyclothiazide (Sun et al., 2002) and aniracetam (Jin et al., 2005). Much less is known about allosteric modulation of KARs. Concanavalin A and a few other plant lectins have been identified as positive allosteric modulators (Partin et al., 1993; Bowie et al., 2003). Sodium and chloride ions are essential for proper KAR function by stabilizing the LBD dimer interface (Paternain et al., 2003; Plested and Mayer, 2007; Plested et al., 2008). Interestingly, zinc ions have a unique, potentiating effect selective for the KAR subunit GluK3 upon binding to the LBD dimer interface (Veran et al., 2012).

Here, we seek to identify small molecules acting as positive allosteric modulators of KARs. Novel 1,2,4-benzothiadiazine 1,1-dioxides (BTDs), which are structurally related to the BTD reference compound 7-chloro-3-methyl-3,4-dihydro-2H-1,2,4benzothiadiazine 1,1-dioxide (IDRA21) (Fig. 1), act as positive allosteric modulators of the AMPARs (Francotte et al., 2007, 2008, 2010, 2013, 2014; Krintel et al., 2012, 2016; Nørholm et al., 2013, 2014; Larsen et al., 2016). Starting from IDRA21, removal of the methyl group at the 3-position and introduction of a short alkyl chain at the 4-position of the BTD scaffold was responsible for a marked improvement of in vitro and in vivo activity on AMPARs, as was observed with 7-halo-substituted compounds, such as the 7-fluoro derivative 4-ethyl-7-fluoro-3,4-dihydro- $2 H$ 1,2,4-benzothiadiazine 1,1-dioxide (BPAM97) (Francotte et al., 2007). Pharmacokinetic properties (metabolic stability) were subsequently improved by introducing a monofluoroethyl chain at the 4-position of the heterocycle, providing compounds such as 7-chloro4-(2-fluoroethyl)-3,4-dihydro-2H-1,2,4-benzothiadiazine 1,1-dioxide (BPAM121) (Francotte et al., 2010). A further improvement of the pharmacokinetic profile as well as the biologic activity was reached with 4-cyclopropyl-substituted BTDs, among which 4-cyclopropyl-7-fluoro-3,4-dihydro-2H-1,2,4-benzothiadiazine 1,1-dioxide (BPAM344) emerged as a very interesting compound (Nørholm et al., 2013). A more recent evolution occurred with the

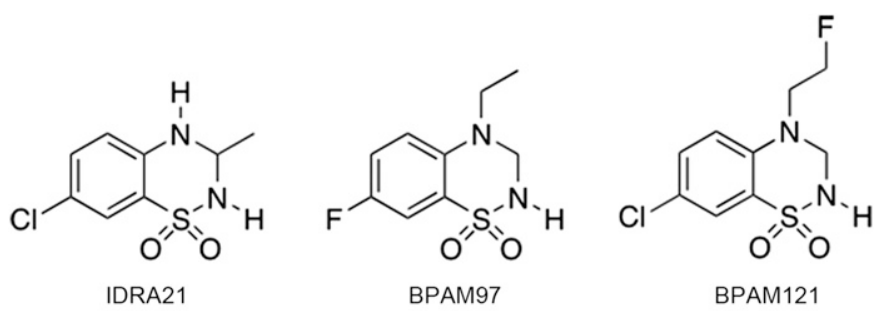

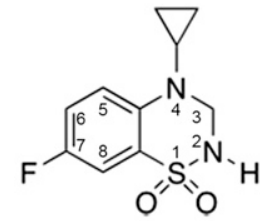

BPAM344

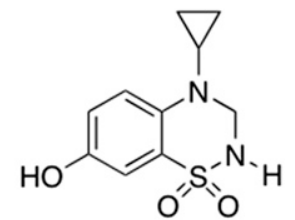

BPAM521
Fig. 1. Structures of IDRA21, BPAM97, BPAM344, BPAM521, and BPAM121. Atom numbering is shown for BPAM344. discovery of potent AMPAR modulators, such as 4-cyclopropyl7-hydroxy-3,4-dihydro-2H-1,2,4-benzothiadiazine 1,1-dioxide (BPAM521), bearing a hydroxyl group at the 7-position of the heterocycle (Krintel et al., 2016). Several of the BTDs were cocrystallized with the LBD of the GluA2 subunit of AMPARs, showing that all of these compounds have the same binding mode at the level of the LBD dimer interface (Krintel et al., 2012, 2016; Nørholm et al., 2013, 2014; Francotte et al., 2014; Larsen et al., 2016). Due to structural analogy between AMPARs and KARs, we tested whether the structurally simple and low-molecularweight compounds BPAM121, BPAM344, and BPAM521 may act as possible positive allosteric modulators of KARs.

\section{Materials and Methods}

All chemicals and reagents were from Sigma-Aldrich (St. Louis, MO) and were of analytical grade unless otherwise stated. BPAM121 (Francotte et al., 2010), BPAM344 (Nørholm et al., 2013), and BPAM521 (Krintel et al., 2016) were synthesized as previously described.

Cell Culture and Transfection. HEK293 cells (European Collection of Cell Cultures, Public Health England, Salisbury, UK) were cotransfected using the Effectene Kit (Qiagen, Hilden, Germany) with green fluorescent protein and GluK1b, GluK2a $(Q)$, GluK3a, or GluA1 at a cDNA ratio of 1:5 (GluK1b, GluK2a, GluA1 $1_{i}$ ) or 1:6 (GluK3a). Cells were used 2-3 days after transfection and plated on polylysine-coated coverslips the day before the experiment for whole-cell recording, or 1-2 days before recordings for outside-out patches.

Electrophysiology. Cells were placed in a chamber perfused with HEPES-buffered solution containing $145 \mathrm{mM} \mathrm{NaCl}, 10 \mathrm{mM}$ HEPES, $2 \mathrm{mM} \mathrm{KCl}, 2 \mathrm{mM} \mathrm{MgCl}, 2 \mathrm{mM} \mathrm{CaCl}_{2}$, and $10 \mathrm{mM}$ glucose, adjusted to $310 \mathrm{mOsm} / \mathrm{l}$ and $\mathrm{pH} 7.4$ with $\mathrm{NaOH}$, at room temperature. Recording pipettes (resistance 3-6 $\mathrm{M} \Omega$ ) were filled with an intracellular solution containing $120 \mathrm{mM} \mathrm{CsCH}_{3} \mathrm{SO}_{3}, 2 \mathrm{mM} \mathrm{NaCl}, 3 \mathrm{mM} \mathrm{MgCl}_{2}, 10 \mathrm{mM}$ EGTA, $10 \mathrm{mM}$ HEPES, and $4 \mathrm{mM} \mathrm{Na} \mathrm{m}_{2} \mathrm{ATP}$, adjusted to $300 \mathrm{mOsm} / \mathrm{l}$ and $\mathrm{pH} 7.2$ with $\mathrm{CsOH}$. Isolated, brightly fluorescent cells were chosen for recording at room temperature. The membrane potential was held at -80 to $-20 \mathrm{mV}$ in whole-cell or outside-out patch-clamp mode. Cells or outside-out patches were placed under a double-barrel pipette mounted on a piezo-electric translator (P-245.50 and E-470 amplifier; Polytec PI, Châtillon, France). In whole-cell recordings, the membrane capacitance and series resistance were compensated at $80 \%$. The modulator was added to both glutamate solution and HEPES-buffered solution (control), and up to three different concentrations of modulator were applied to a cell or outside-out patches during one experiment using a manual valve. Modulator solutions were prepared on the day of experiment from a $1 \mathrm{M}$ stock solution in dimethylsulfoxide. Glutamatergic receptor-mediated currents were evoked by long $(800 \mathrm{~ms})$ or short $(1 \mathrm{~ms})$ applications of glutamate $(1-10 \mathrm{mM})$ every 20 seconds (20- to 150 -second intervals, depending on modulator concentration), filtered at $2.9 \mathrm{kHz}$, and recorded at a sampling frequency of $20 \mathrm{~Hz}$ by an EPC9 amplifier (HEKA Elektronik Dr. Schulze GmbH, Ludwigshafen/Rhein, Germany).

Data Analysis. IGOR Pro (version 6.22A; WaveMetrics Inc., Lake Oswego, OR) was used for data analysis of recorded traces. The baseline was corrected manually. Peak current amplitudes were measured from the average trace of five stable sweeps using standard functions in the software. Decay time $(\tau)$ was assessed by fitting the current trace with a two-exponential equation:

$$
\mathrm{F}=\mathrm{Y} 0+\mathrm{A} 1^{*} \exp [-(\mathrm{x}-\mathrm{X} 0) / \mathrm{T} 1]+\mathrm{A} 2^{*} \exp [-(\mathrm{x}-\mathrm{X} 0) / \mathrm{T} 2]
$$

giving the weighted tau $(\tau)$ as:

$$
\tau=\left(\mathrm{A} 1^{*} \mathrm{~T} 1+\mathrm{A} 2^{*} \mathrm{~T} 2\right) /(\mathrm{A} 1+\mathrm{A} 2) .
$$

GraphPad Prism (version 5.0c for Mac OS X; GraphPad Software, San Diego, CA) was used for curve fitting by nonlinear regression, bar 
graph plots, and statistical analysis. One-way analysis of variance with Bonferroni's post test was used to assess differences between modulators or receptor subtypes, and paired Student's $t$ test was used for assessment of difference in amplitude and decay times, with the following coding: $* * * P<0.001$; $* * P<0.01$; $* P<0.05$; ns (not significant), $P>0.05$. Data are presented as the mean \pm S.E.M. in both the text and figures.

Crystallization. Rat GluK1-LBD, comprising LBD segment S1 residues 430-544 and segment S2 residues 667-805 connected by a glycine-threonine linker (UNP P22756, numbering including signal peptide), was expressed and purified as previously described (Naur et al., 2005). The protein was dissolved in $10 \mathrm{mM}$ HEPES ( $\mathrm{pH} 7.0$ ), $20 \mathrm{mM} \mathrm{NaCl}$, and $1 \mathrm{mM}$ EDTA.

BPAM121, BPAM344, and BPAM521 were added to the protein solution as solid compound. The protein solution was equilibrated at $6^{\circ} \mathrm{C}$ for at least 24 hours prior to setting up drops. Protein-ligand complexes were crystallized by the hanging-drop vapor-diffusion method at $6^{\circ} \mathrm{C}$. The reservoir volume was $500 \mu \mathrm{l}$. For crystallization of BPAM121 with GluK1-LBD, a protein concentration of $4.4 \mathrm{mg} / \mathrm{ml}$ was used containing $10 \mathrm{mM}$ kainate. The drop consisted of $1 \mu \mathrm{l}$ of protein solution and $1 \mu \mathrm{l}$ of reservoir solution [20\% polyethylene glycol 4000 (PEG4000), $0.3 \mathrm{M} \mathrm{Li}_{2} \mathrm{SO}_{4}$, and $0.1 \mathrm{M} \mathrm{NaOAc,} \mathrm{pH} \mathrm{5.5].}$ For crystallization of BPAM344 with GluK1-LBD, a protein concentration of $5.8 \mathrm{mg} / \mathrm{ml}$ was used containing $10 \mathrm{mM}$ kainate. The drop consisted of $1 \mu \mathrm{l}$ of protein solution and $2 \mu \mathrm{l}$ of reservoir solution (15.2\% PEG4000, 0.3 $\mathrm{M} \mathrm{Li}_{2} \mathrm{SO}_{4}$, and 0.1 M NaOAc, pH 5.5). For crystallization of BPAM521 with GluK1-LBD, a protein concentration of $4.6 \mathrm{mg} / \mathrm{ml}$ was used containing $8.3 \mathrm{mM}$ kainate. The drop consisted of $1 \mu \mathrm{l}$ of protein solution and $1 \mu \mathrm{l}$ of reservoir solution (16\% PEG4000, $0.2 \mathrm{M} \mathrm{Li}_{2} \mathrm{SO}_{4}$, and $0.1 \mathrm{M}$ phosphate-citrate, $\mathrm{pH}$ 4.5). Crystals were briefly submerged in the reservoir solution containing 20-30\% glycerol as cryoprotectant and flash cooled in liquid nitrogen before storage.
Structure Determination. X-ray diffraction data were collected at beamline I911-3 (MAX-Laboratory, Lund, Sweden) (Ursby et al., $2013)$ at a cryogenic temperature (100 K). Data were processed using XDS (Kabsch, 2010) and SCALA (Evans, 2006) in the CCP4 suite of programs (Winn et al., 2011). The structures were solved by molecular replacement in PHASER (McCoy et al., 2007) using the structure of GluK1-LBD in complex with kainate (Protein Data Bank identifier 4e0x, chain A). Initial model building was performed using AUTOBUILD (Terwilliger et al., 2008) in PHENIX (Adams et al., 2010), and water molecules were introduced into the structures at this step. During iterative rounds of model building in COOT (Emsley et al., 2010) and refinement in PHENIX, kainate, modulators, glycerol, ions, and additional water molecules were gradually built into the structures. Ligand coordinate files were generated in MAESTRO (version 9.4; Schrödinger, LLC, New York, NY), and topology and parameter files were generated in eLBOW (Moriarty et al., 2009). Data collection and refinement statistics are given in Table 1.

Domain closures were calculated relative to a GluK1-LBD structure with an antagonist (Protein Data Bank identifier 3s2v, chain B) using the DynDom server (Hayward and Berendsen, 1998). All structure figures were prepared in PyMOL (version 1.7; PyMOL Molecular Graphics System, V.S., LLC, pymol.org).

\section{Results}

Three BTD compounds (BPAM121, BPAM344, and BPAM521) (Fig. 1) were tested as potential positive allosteric modulators of recombinant KARs expressed in HEK293 cells using whole-cell and outside-out patch-clamp recordings. Interaction of the compounds with KARs at the molecular level was investigated by solving high-resolution X-ray crystal structures of each compound bound to the GluK1-LBD dimer.

TABLE 1

Crystal data, data collection, and refinement statistics of GluK1-LBD in complex with kainate and BPAM344, BPAM121, or BPAM521

\begin{tabular}{|c|c|c|c|}
\hline Complex & BPAM 344 & BPAM121 & BPAM521 \\
\hline \multicolumn{4}{|l|}{ Crystal data } \\
\hline PDB ID & $5 \mathrm{MFQ}$ & $5 \mathrm{MFW}$ & $5 \mathrm{MFV}$ \\
\hline Space group & $P 4_{1} 2_{2} 2$ & $P 4_{1} 2_{1} 2$ & $P 4{ }_{1} 2{ }_{1} 2$ \\
\hline Unit cell: $a, b, c(\AA)$ & $71.01,71.01,234.85$ & $68.64,68.64,234.85$ & $68.77,68.77,232.89$ \\
\hline Molecules in a.u. ${ }^{a}$ & 2 & 2 & 2 \\
\hline \multicolumn{4}{|l|}{ Data collection } \\
\hline Wavelength $(\AA)$ & 0.97916 & 1.00000 & 0.97879 \\
\hline Resolution $(\AA)$ & $\begin{array}{l}29.43-1.90 \\
(2.00-1.90)^{b}\end{array}$ & $\begin{array}{l}29.43-2.10 \\
(2.21-2.10)^{b}\end{array}$ & $\begin{array}{l}47.61-2.18 \\
(2.30-2.18)^{b}\end{array}$ \\
\hline No. of unique reflections & $48,493(6941)$ & $33,935(4833)$ & $29,453(3750)$ \\
\hline Average redundancy & $8.1(8.2)$ & $8.2(7.1)$ & $5.8(2.5)$ \\
\hline Completeness $(\%)$ & $100(100)$ & $99.9(99.9)$ & $97.8(97.8)$ \\
\hline$R_{\text {merge }}^{c}$ & $0.072(0.316)$ & $0.086(0.372)$ & $0.074(0.152)$ \\
\hline $\mathrm{I} / \sigma \mathrm{I}$ & $8.0(2.2)$ & $7.0(2.0)$ & $7.1(4.6)$ \\
\hline Wilson B $\left(\AA^{2}\right)$ & 17 & 23 & 25 \\
\hline \multicolumn{4}{|l|}{ Refinement } \\
\hline Amino acid residues $(A / B)$ & $253 / 254$ & $249 / 253$ & $250 / 251$ \\
\hline Kainate/modulator/chloride/sulfate/glycerol/ acetate/water & $2 / 2 / 1 / 2 / 3 /-/ 582$ & $2 / 2 / 1 / 5 / 2 / 1 / 476$ & $2 / 2 / 1 / 3 / 1 / 1 / 324$ \\
\hline$R_{\text {work }}^{d} / R_{\text {free }}{ }^{e}(\%)$ & $15.5 / 19.5$ & $16.3 / 21.9$ & $16.7 / 21.5$ \\
\hline \multicolumn{4}{|l|}{ Average $B$ values $\left(\AA^{2}\right)$ for: } \\
\hline Amino acid residues $(A / B)$ & $22 / 22$ & $17 / 19$ & $30 / 30$ \\
\hline Kainate/modulator/chloride/sulfate/glycerol/ acetate/water & $14 / 11 / 26 / 77 / 41 / 32$ & $8 / 17 / 30 / 50 / 25 / 39 / 23$ & $17 / 20 / 32 / 61 / 43 / 39 / 30$ \\
\hline R.M.S. deviation bond lengths $(\AA) /$ angles $\left({ }^{\circ}\right)$ & $0.006 / 1.1$ & $0.006 / 1.0$ & $0.008 / 1.0$ \\
\hline Ramachandran outliers/favored (\%) & $0.0 / 98.3$ & $0.2 / 99.0$ & $0.0 / 98.4$ \\
\hline Rotamer outliers $(\%) / \mathrm{C} \beta$ outliers $(\%) /$ clash score $^{f}$ & $1.5 / 0 / 1.9$ & $0.89 / 0 / 1.7$ & $1.6 / 0 / 2.0$ \\
\hline
\end{tabular}

PDB ID, Protein Data Bank identifier.

$a^{a}$ a.u. is the asymmetric unit of the crystal.

${ }^{b}$ Values in parentheses correspond to the outermost resolution shell.

${ }^{c} R_{\text {merge }}$ is calculated as follows: $\mathrm{I}_{i}(h k l)$ is the intensity of an individual measurement of the reflection with Miller indices $h k l$, and $\mathrm{I}(h k l)$ is the intensity from multiple observations. $R_{\text {merge }}=\sum_{h k l} \sum_{i}\left|\mathrm{I}_{i}(h k l)-\mathrm{I}(h k l)\right| / \sum_{h k l} \sum_{i}\left|\mathrm{I}_{i}(h k l)\right|$

${ }^{d} R_{\text {work }}=\sum_{h k l}\left|\mathrm{~F}_{\text {obs }}-\mathrm{F}_{\text {calc }}\right| / \sum_{h k l}\left|\mathrm{~F}_{\text {obs }}\right|$, where $\mathrm{F}_{\text {obs }}$ and $\mathrm{F}_{\text {calc }}$ are the observed and calculated structure factor amplitudes, respectively, for reflection $h k l$. ${ }^{e} R_{\text {free }}$ is equivalent to $R_{\text {work }}$, but calculated with $5 \%$ of reflections omitted from the refinement process.

$f_{\text {MolProbity statistics (Chen et al., 2010). }}$ 
A - Whole-cell patch $1 \mathrm{mM} \mathrm{Glu}+100$ uM BPAM344

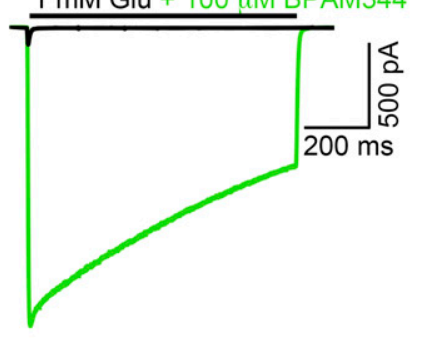

C- Outside-out patch
$1 \mathrm{mM} \mathrm{Glu}+100$ uM BPAM344

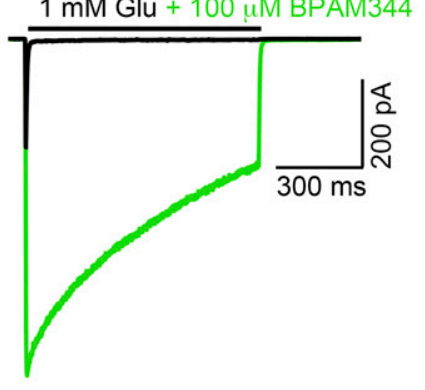

E- Outside-out patch 1 mM Glu + 100 uM BPAM344

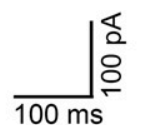

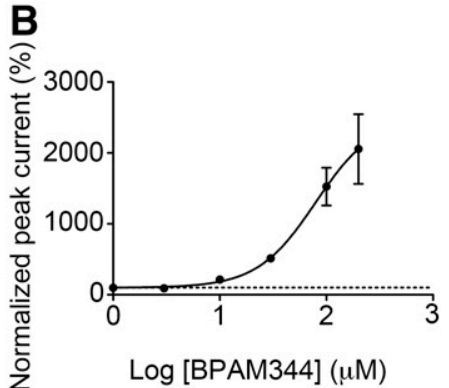

D

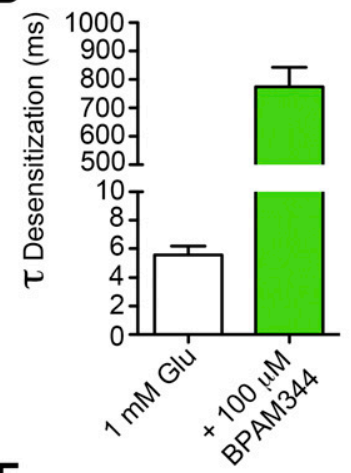

$\mathbf{F}$

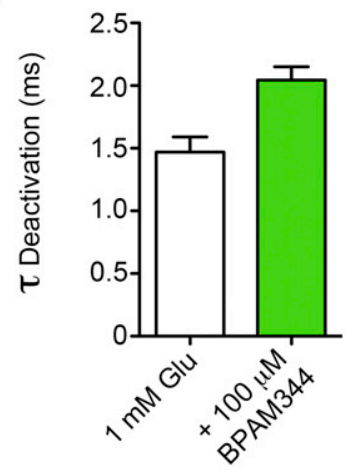

Fig. 2. BPAM344 potentiation of glutamate-evoked responses at GluK2a. (A) Example traces of the glutamate-evoked responses (1 mM for $800 \mathrm{~ms}$ ) in the absence (black) and presence (green) of $100 \mu \mathrm{M}$ BPAM344 in GluK2a whole-cell patches. (B) Concentration-response relationship of glutamateevoked responses ( $1 \mathrm{mM}$ for $800 \mathrm{~ms}$ ) in GluK2a whole-cell recordings. Peak currents in the presence of increasing concentrations of BPAM344 are normalized to the glutamate-evoked response without modulator. Data points are given as the mean \pm S.E.M. of several recordings $(n=4-7)$ at each modulator concentration. (C and D) Effect of BPAM344 on desensitization kinetics of glutamate-evoked responses $(1 \mathrm{mM})$ for GluK2a outside-out patches of HEK293 cell membrane. Eight hundred-millisecond glutamate applications were used. (C) Example traces of the glutamate-evoked responses in the absence (black) and presence (green) of $100 \mu \mathrm{M}$ BPAM344. (D) BPAM344 $(100 \mu \mathrm{M}$, green bar) significantly $(P<0.001)$ increases the decay time of receptor desensitization compared with the response evoked by glutamate alone (white bar). Decay time $(\tau)$ is given as the mean \pm S.E.M. $(n=5)$. (E and F) Effect of BPAM344 on deactivation kinetics of glutamateevoked responses $(1 \mathrm{mM})$ for GluK2a outside-out patches of HEK293 cell membrane. One-millisecond glutamate applications were used. (E) Example traces of the glutamate-evoked responses in the absence (black) and presence (green) of $100 \mu \mathrm{M}$ BPAM344. (F) BPAM344 (100 $\mu \mathrm{M}$, green bar) also has a significant effect $(P<0.001)$ on deactivation decay time. Decay time $(\tau)$ is given as the mean \pm S.E.M. $(n=5)$.

BPAM344 Is a Potent Positive Allosteric Modulator of GluK2a. The effect of BPAM344 on the measured peak current amplitude of GluK2a homomeric KARs was established using whole-cell recording and rapid solution exchange on lifted cells. In control conditions, a long (800 ms) pulse of
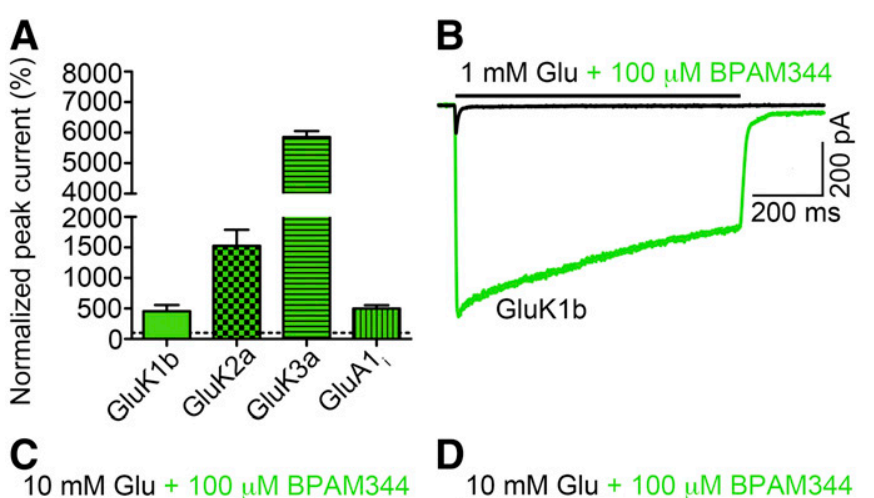

D $10 \mathrm{mM} \mathrm{Glu}+100 \mu \mathrm{M}$ BPAM344

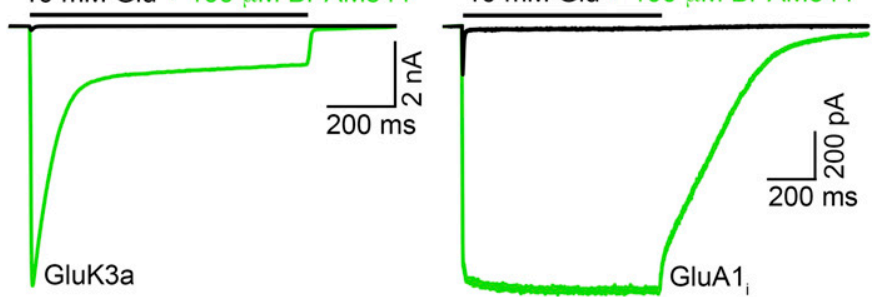

Fig. 3. Modulatory effects of BPAM344 at the kainate receptors GluK1b, GluK2a, and GluK3a and the AMPA receptor GluA1 $1_{i}$. (A) BPAM344 significantly potentiates the peak current amplitude of GluK3a compared with GluK1b, GluK2a, and GluA1 $(P<0.001)$, and GluK2a compared with GluK1b and GluA1 $1_{\mathrm{i}}(P<0.05)$. There is no significant difference $(P>0.05)$ between GluK1b and GluA1 $1_{\mathrm{i}}$. (B-D) Example traces of the glutamateevoked responses in the absence (black) and presence (green) of $100 \mu \mathrm{M}$ BPAM344 on whole-cell recordings. Glutamate was applied for $800 \mathrm{~ms}$. (B) GluK1b. (C) GluK3a. (D) GluA1 $1_{i}$.

glutamate $(1 \mathrm{mM})$ evoked a transient response with a decay time constant of less than $10 \mathrm{~ms}$, as previously reported (Perrais et al., 2010). Application of BPAM344 (100 $\mu \mathrm{M})$ caused a major increase in the peak amplitude of the response to glutamate and an increase in its decay (Fig. 2A). At the highest concentration of modulator tested $(200 \mu \mathrm{M})$, BPAM344 was found to potentiate the glutamate-evoked current by 21-fold. An upper plateau for the potentiation of peak current amplitude could not be reached due to the low solubility of the modulator at higher concentrations. The potency $\left(\mathrm{EC}_{50}\right.$, corresponding to the concentration of modulator responsible for $50 \%$ of the maximal effect) was estimated as $79 \pm 2 \mu \mathrm{M}$ (Fig. 2B). Measured using outside-out patches, the decay time of desensitization of the glutamate-evoked response $(1 \mathrm{mM})$ was increased from $5.5 \pm 0.6$ to $774.7 \pm 68.0 \mathrm{~ms}$ in the presence of BPAM344 $(100 \mu \mathrm{M})$ (Fig. 2, C and D). BPAM344 was also tested on GluK2a currents evoked by a short ( $1 \mathrm{~ms}$ ) pulse of glutamate to evaluate the effects of the compound on deactivation kinetics. BPAM344 induced a moderate increase in amplitude and a slight decrease in the estimated decay time of deactivation $(1.5 \pm 0.1 \mathrm{~ms}$ without BPAM344 present and $2.0 \pm 0.1 \mathrm{~ms}$ with BPAM344 present, $P<0.001$, Fig. $2, \mathrm{E}$ and $\mathrm{F}$ ). Because of the fast desensitization kinetics of KAR subunits, the increase in peak current recorded in our experimental conditions most likely reflects an effect on receptor desensitization rather than an effect on activation kinetics (Perrais et al., 2009). Our data are consistent with a robust effect of BPAM344 on desensitization of KARs.

Comparative Effects of BPAM344 on Other KAR Subunits and on the AMPAR Subunit GluA1. Next, we tested the effects of BPAM344 on the recombinantly expressed KAR subunits GluK1b and GluK3a. BPAM344 (100 $\mu \mathrm{M})$ increased the peak amplitude of GluK1b currents evoked by 
A $1 \mathrm{mM} \mathrm{Glu}+100 \mu \mathrm{M}$ BPAM521
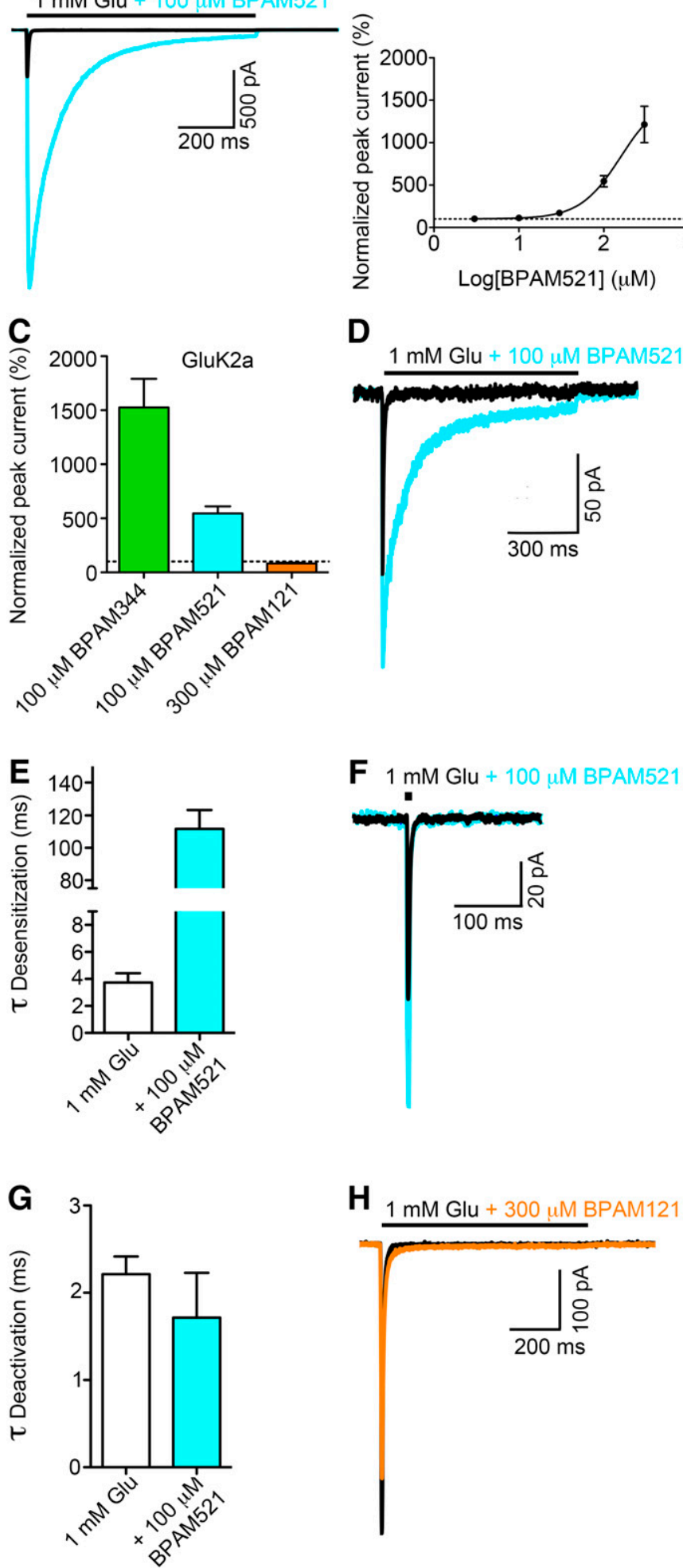

Fig. 4. BPAM521 and BPAM121 potentiation of glutamate-evoked responses at GluK2a. (A) Example traces of the glutamate-evoked responses $(1 \mathrm{mM}$ for $800 \mathrm{~ms}$ ) in the absence (black) and presence (blue) of $100 \mu \mathrm{M}$ BPAM521 in GluK2a whole-cell recordings. (B) Concentration-response relationship of glutamate-evoked responses ( $1 \mathrm{mM}$ for $800 \mathrm{~ms}$ ) in GluK2a whole-cell recordings. Peak currents in the presence of increasing concentrations of BPAM521 are normalized to the glutamate-evoked response without modulator. Data points are given as the mean \pm S.E.M. of several recordings $(n=6)$ at each modulator concentration. (C) Effects of BPAM344 (100 $\mu \mathrm{M}$, green bar), BPAM521 (100 $\mu \mathrm{M}$, blue bar), and BPAM121 glutamate (1 mM) by 5-fold (Fig. 3A) and markedly slowed down the decay kinetics of desensitization (from $42 \pm 15$ to $832 \pm 64 \mathrm{~ms}$ in the presence of BPAM344 for whole-cell configuration; Fig. 3B). As previously reported, $1 \mathrm{mM}$ glutamate did not evoke any detectable current in GluK3aexpressing cells (Schiffer et al., 1997), likely due to fast desensitization of partially bound receptors (Perrais et al., 2009). We observed that, in the presence of BPAM344, application of $3 \mathrm{mM}$ glutamate led to the activation of a substantial current with slow decay (data not shown). To estimate the magnitude of potentiation of GluK3a currents by BPAM344, we used a concentration of glutamate of $10 \mathrm{mM}$. We observed a 59-fold potentiation of glutamate-evoked currents for GluK3a in the presence of BPAM344 (100 $\mu \mathrm{M})$ (Fig. 3C). For comparison, $100 \mu \mathrm{M}$ BPAM344 led to a 15-fold potentiation of the glutamateevoked GluK2a currents. Thus, BPAM344 exerts a major effect on the three KAR subunits, GluK1b, GluK2a, and GluK3a, both on the peak amplitude of the response and on the decay kinetics. Moreover, the positive allosteric modulatory effect of BPAM344 is reversible at the three KAR subtypes. The time course for full recovery after washout of BPAM344 is $15.4 \pm 2.2$ minutes at GluK1b, $29.2 \pm 4.2$ minutes at GluK2a, and $38.2 \pm 0.9$ minutes at GluK3a.

The potentiating effect of BPAM344 was, however, not restricted to KAR subunits; it caused a 5-fold increase in the peak amplitude of the current evoked by glutamate $(10 \mathrm{mM})$ in HEK293 cells expressing the AMPAR subunit GluA1 $1_{i}$. In addition, the current did not decay during the $800-\mathrm{ms}$ pulse (Fig. 3D) and only slowly decayed after the exposure to glutamate was ceased, suggesting that BPAM344 has a positive modulatory effect on both desensitization and deactivation of the GluA1 $1_{i}$ receptor.

Small Modifications in Modulator Structure Greatly Influence Modulatory Effect. We then investigated the impact of small modifications of BPAM344, and more specifically the role of the substituent in the 4- and 7-positions of BPAM344. We characterized the potency of two variants of BPAM344, BPAM121, and BPAM521 on GluK2a (Fig. 4). The only structural difference between BPAM521 and BPAM344 is the substituent in the 7-position, with a hydroxyl group in BPAM521 and a fluorine atom in BPAM344. BPAM521 was found to potentiate the peak current amplitude of GluK2a 12 -fold at a concentration of $300 \mu \mathrm{M}$ (Fig. 4B). Again, a valid $\mathrm{EC}_{50}$ value (potency estimated at $159 \pm 3 \mu \mathrm{M}$ ) could not be

(300 $\mu \mathrm{M}$, orange bar) on GluK2a whole-cell recordings. BPAM344 significantly modulates currents compared with BPAM521 and BPAM121 $(P<0.01)$. (D and E) Effect of BPAM521 on desensitization kinetics (800-ms application) of glutamate-evoked responses $(1 \mathrm{mM})$ for GluK2a outside-out patches of HEK293 cell membrane. (D) Example traces of the glutamate-evoked responses in the absence (black) and presence (blue) of $100 \mu \mathrm{M}$ BPAM521. (E) BPAM521 (100 $\mu \mathrm{M}$, blue bar) significantly $(P<$ 0.001 ) increases the decay time of receptor desensitization compared with the response evoked by glutamate alone (white bar). Decay time $(\tau)$ is given as the mean \pm S.E.M. $(n=6)$. (F and G) Effect of BPAM521 on deactivation kinetics (1-ms glutamate application) of glutamate-evoked responses $(1 \mathrm{mM})$ for GluK2a outside-out patches of HEK293 cell membrane. (F) Example traces of the glutamate-evoked responses in the absence (black) and presence (blue) of $100 \mu \mathrm{M}$ BPAM521. (G) BPAM521 (100 $\mu \mathrm{M}$, blue bar) has no significant effect $(P>0.05)$ on deactivation decay time. Decay time $(\tau)$ is given as the mean \pm S.E.M. $(n=5)$. $(\mathrm{H})$ Example traces of the glutamate-evoked responses (1 mM for $800 \mathrm{~ms}$ ) in the absence (black) and presence (orange) of $300 \mu \mathrm{M}$ BPAM121 in GluK2a whole-cell recordings. 
determined because a plateau could not be reached due to limited solubilization of the compound (Fig. 4B). BPAM521 caused an increase in the decay time of desensitization measured in outside-out patches from $3.7 \pm 0.7$ to $111.8 \pm$ $11.6 \mathrm{~ms}$ in the presence of the modulator (Fig. 4, D and E). BPAM521 did not affect the time course of deactivation $(2.2 \pm$ $0.2 \mathrm{~ms}$ in control vs. $1.7 \pm 0.5 \mathrm{~ms}$ in the presence of modulator; $P>0.05$; Fig. 4, F and G). The effect of BPAM521 is also reversible with a time course for full recovery following a washout of $12.8 \pm 0.7$ minutes at GluK2a. Compared with BPAM344, BPAM121 contains a fluoroethyl substituent in the 4-position and a chlorine atom in the 7-position of the BTD scaffold. No potentiation of the glutamate-evoked response was observed for BPAM121 at the highest concentration of modulator tested (300 $\mu \mathrm{M}$; Fig. 4, C and $\mathrm{H}$ ). In addition, BPAM121 was without effect $(4.7 \pm 0.8 \mathrm{~ms}$ in control vs. $7.4 \pm$ $1.7 \mathrm{~ms}$ in the presence of modulator, $n=3, P>0.05$ ) on the desensitization (800-ms glutamate pulse) and on the deactivation time course (1-ms glutamate application; $2.3 \pm 0.2 \mathrm{~ms}$ in control vs. $2.6 \pm 0.3 \mathrm{~ms}$ in the presence of modulator, $n=3$, $P>0.05)$ when tested in the whole-cell configuration.

The Modulators Bind at the KAR LBD Dimer Interface. As crystallization with GluK2-LBD was not successful in our hands, we turned to crystals of GluK1-LBD. Structures of all three BTD compounds bound to the ligandbinding domain of GluK1 were determined by X-ray crystallography to resolutions of 1.9-2.2 $\AA$. In the presence of kainate, GluK1-LBD forms a dimer (Plested et al., 2008; Venskutonytè et al., 2012). Therefore, we crystallized GluK1-LBD with kainate and BPAM344. The complex crystallized with a GluK1-LBD dimer in the asymmetric unit, where kainate was seen to bind at the orthosteric-binding site in both subunits of the dimer (Fig. 5). Two molecules of BPAM344 bind at the dimer interface in a site located around a pseudo 2-fold symmetry axis (Fig. 5). One chloride ion is bound at the well characterized anion-binding site (Plested and Mayer, 2007), whereas water molecules were most likely present at the two cation-binding sites (Plested et al., 2008) (Fig. 5).

One direct hydrogen bond is established from the sulfonamide $\mathrm{N}$ atom of BPAM344 to the backbone $\mathrm{O}$ atom of Pro532 (Fig. 6A). Furthermore, a water (W1)-mediated polar contact is seen from one $\mathrm{O}$ atom of the BPAM344 sulfonamide to the side-chain $\mathrm{N}$ atom of Gln786. In addition to polar contacts, multiple van der Waals (vdW) interactions between BPAM344 and surrounding residues (within $4 \AA$ ) from both subunits are seen. The sulfonamide $\mathrm{O}$ atoms are engaged in vdW interactions with Lys531, Pro532, and Leu783 in one subunit of the dimer, as well as Ile519 and Lys762 and in the opposite subunit. The cyclopropyl group of BPAM344 is believed to have some $\pi$-character (Galano et al., 2007) and, thus, can form stacking interactions with the backbone atoms of Phe533Thr535. Additional vdW interactions are seen from the cyclopropyl group with the side chains of Thr535, Gln786, and Leu791 in one subunit and Ser761 in the opposite subunit. Stacking interactions are also seen from the aromatic ring of BPAM344 with the peptide backbone of Lys762-Gly763 of the opposite subunit. All of these nonpolar interactions between BPAM344 and the receptor further stabilize the GluK1-LBD dimer interface in the active conformation.

We then determined the structure of GluK1-LBD in complex with kainate and BPAM521. As in the GluK1-LBD structure with BPAM344, two molecules of BPAM521 bind at the interface of the GluK1-LBD dimer. The BTD scaffold of BPAM521 is located very similar to that of BPAM344 and forms many of the same interactions with GluK1 residues (Fig. 6B). The largest differences between the two structures are at Thr535, Ser761, and Gln786, which adopt different conformations upon binding of BPAM344 and BPAM521, respectively (Fig. 6, $\mathrm{A}$ and $\mathrm{B}$ ).

Similar to the first two structures, the third structure of GluK1-LBD in complex with kainate and BPAM121 revealed that two molecules of BPAM121 are located at the dimer interface. However, BPAM121 only partially occupies the binding site (the occupancy was refined to 69 and $61 \%$ for the two BPAM121 molecules). In the presence of BPAM121, the side chain of Thr535 points away from the modulator site (Fig. 6C).

\section{Discussion}

Functional and structural studies have revealed that endogenous ions and small molecules can modulate iGluR function. Interaction with small-molecule modulators permits activity-dependent changes in receptor function and could potentially be exploited in the development of therapeutics. However, no such small-molecule modulators other than ions are available today that target KARs. Here, we show that two compounds (BPAM344 and BPAM521), previously reported as AMPAR-positive allosteric modulators (Nørholm et al., 2013; Krintel et al., 2016), exert a strong positive modulatory effect on currents mediated by the homomeric KAR subunits GluK1b, GluK2a, and GluK3a. The reversibility of the modulatory effect of BPAM344 and BPAM521 distinguishes this

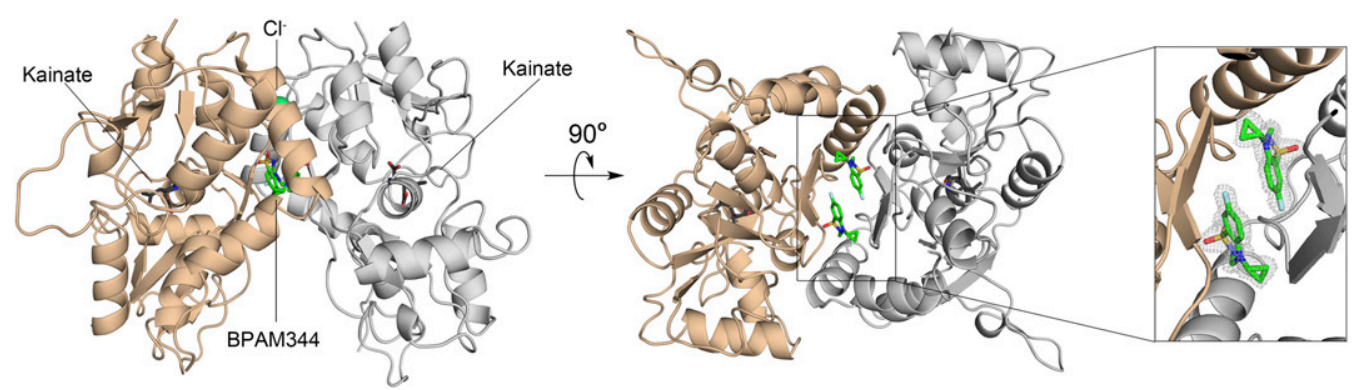

Fig. 5. The structure of GluK1-LBD in complex with kainate and BPAM344. (Left) Side view of the GluK1-LBD dimer (beige and gray) showing that BPAM344 (green sticks) binds in the lower part of the dimer interface. Kainate is shown as black sticks, and the chloride ion as a green sphere. (Middle) A $90^{\circ}$ vertically rotated view. Two subunits of BPAM344 are located around a pseudo 2-fold symmetry axis at the dimer interface. (Right) Zoomed-in image of the modulator-binding site, showing the $2 \mathrm{Fo}-\mathrm{Fc}$ omit electron density map contoured at $1 \sigma$. 

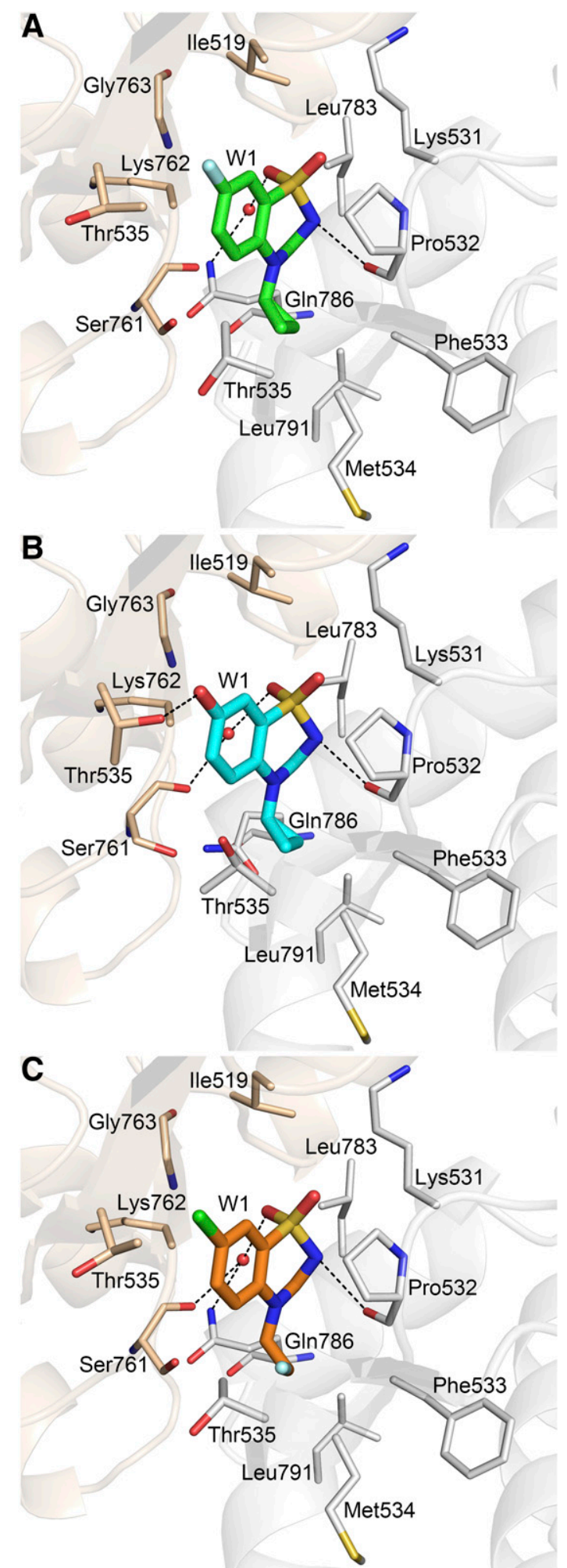

Fig. 6. Interaction of GluK1-LBD residues with BPAM344, BPAM521, and BPAM121. The color coding of GluK1 residues is as in Fig. 5. Water molecules are shown as red spheres, and hydrogen bonds (up to $3.5 \AA$ ) are shown as stippled lines. (A) BPAM344 (green). (B) BPAM521 (cyan). (C) BPAM121 (orange).

new class of KAR modulators from lectins (e.g.,. concanavalin A), which bind at glycosylation sites (Everts et al., 1999) and irreversibly potentiate agonist-evoked currents (Huettner, 1990).
BPAM344 and BPAM521 increase the measured peak amplitude of evoked KAR current by 5 - to 59 -fold, depending on the subunit, and dramatically slow down decay kinetics. The most effective compound, BPAM344 displays larger a effect on potentiation of glutamate-evoked currents at GluK2a and GluK3a compared with at the AMPAR subunit GluA1 $1_{i}$ (3-fold between GluK2a and GluA1 ${ }_{i}$ and 12-fold between GluK3a and $\mathrm{GluA1}_{\mathrm{i}}$ ) (Fig. 3A). The effect of BPAM344 was similar at GluK1b and GluA $1_{\mathrm{i}}$. Interestingly, the third modulator, BPAM121, significantly potentiates the peak current amplitude of AMPARs (Francotte et al., 2010), whereas no potentiation of the glutamate-evoked response at GluK2a receptors was observed (Fig. 4, $\mathrm{C}$ and $\mathrm{H}$ ). This observation highlights that small changes in the modulator structure dramatically influence its efficacy at KARs and AMPARs.

We observed a major effect of BPAM344 and BPAM521 on GluK2a desensitization, with 136- and 30-fold increases in desensitization time, respectively (Figs. $2 \mathrm{D}$ and $4 \mathrm{E}$ ). The variable magnitude of potentiation of the response by BPAM344 (from 5- to 59-fold) for the different KAR subunits appears to correlate with differential desensitization properties; the highly desensitizing GluK3 subunit is 10 times more impacted by BPAM344 than the slowly desensitizing GluK1 subunit. The low sensitivity of GluK3 receptors for glutamate is attributable to fast desensitization of partially bound receptors (Perrais et al., 2009). Strikingly, at a concentration of $3 \mathrm{mM}$ glutamate, BPAM344 revealed an inward current which was otherwise not detectable on GluK3 KARs (data not shown). The major effects of BPAM344 on GluK3a current amplitude and desensitization kinetics are reminiscent of the modulatory effect of zinc (Veran et al., 2012). Both the potentiation of GluK3 currents and the increased decay kinetics by micromolar concentrations of zinc were shown to result from reduced desensitization (Veran et al., 2012). Overall, our results fit well with the possibility that BPAM344 acts by reducing desensitization of KARs. In parallel, we show that deactivation, as indicated by the decay kinetics in response to short pulses of glutamate, is only affected by the BPAM compounds to a minor extent. For the AMPA receptor GluA $_{i}$, we observed an effect of BPAM344 on both desensitization and deactivation. It has previously been suggested that positive allosteric modulators, such as aniracetam, slow deactivation by stabilizing the GluA2-LBD clamshell in its closed-cleft, glutamate-bound conformation (Jin et al., 2005). On the other hand, modulators with a dominant effect on desensitization, such as cyclothiazide, promote dimerization of the GluA2-LBD (Sun et al., 2002).

A soluble construct of the ligand-binding domain was crystallized in complex with kainate and each of the three modulators BPAM121, BPAM344, and BPAM521. The positive allosteric modulator-binding site was found to reside in the lower part of the GluK1 dimer interface, near the D1-D2 hinge region (Fig. 5). Two molecules of BPAM344 are located within $4 \AA$ of each other, with the closest interactions between the 7-fluorine atom of one molecule and the aromatic $\mathrm{C} 6$ atom of the other molecule, as well as between the $\mathrm{C} 6$ atoms (Fig. 7A). Compared with structures of GluK1-LBD without a modulator bound (Plested et al., 2008; Venskutonyte et al., 2011), BPAM344 displaces four to eight water molecules in the dimer interface (Fig. 7B). Through hydrogen-bonding networks combined with vdW interactions, the modulators are anchored between the two subunits, thereby increasing the 
A
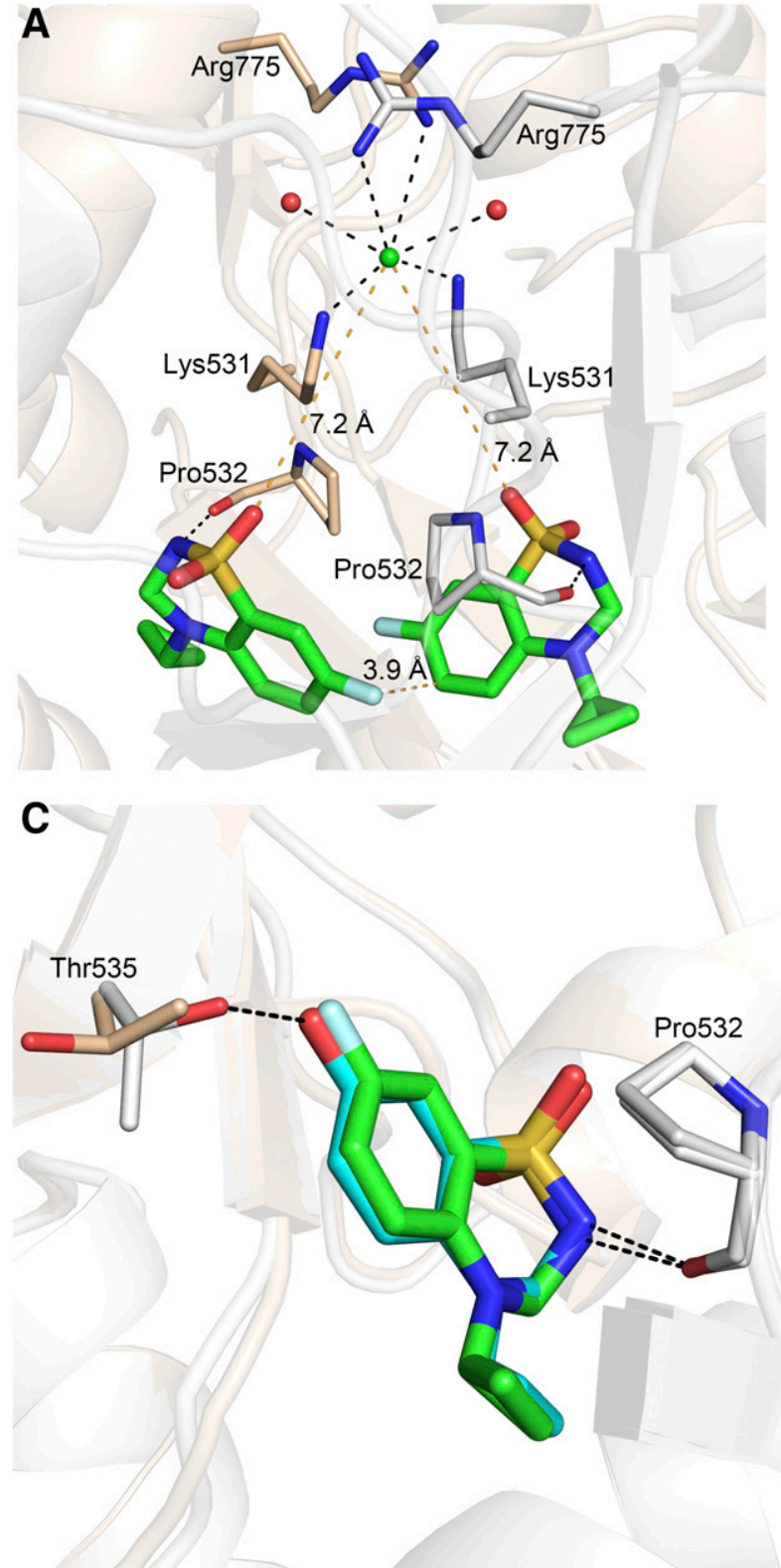

B
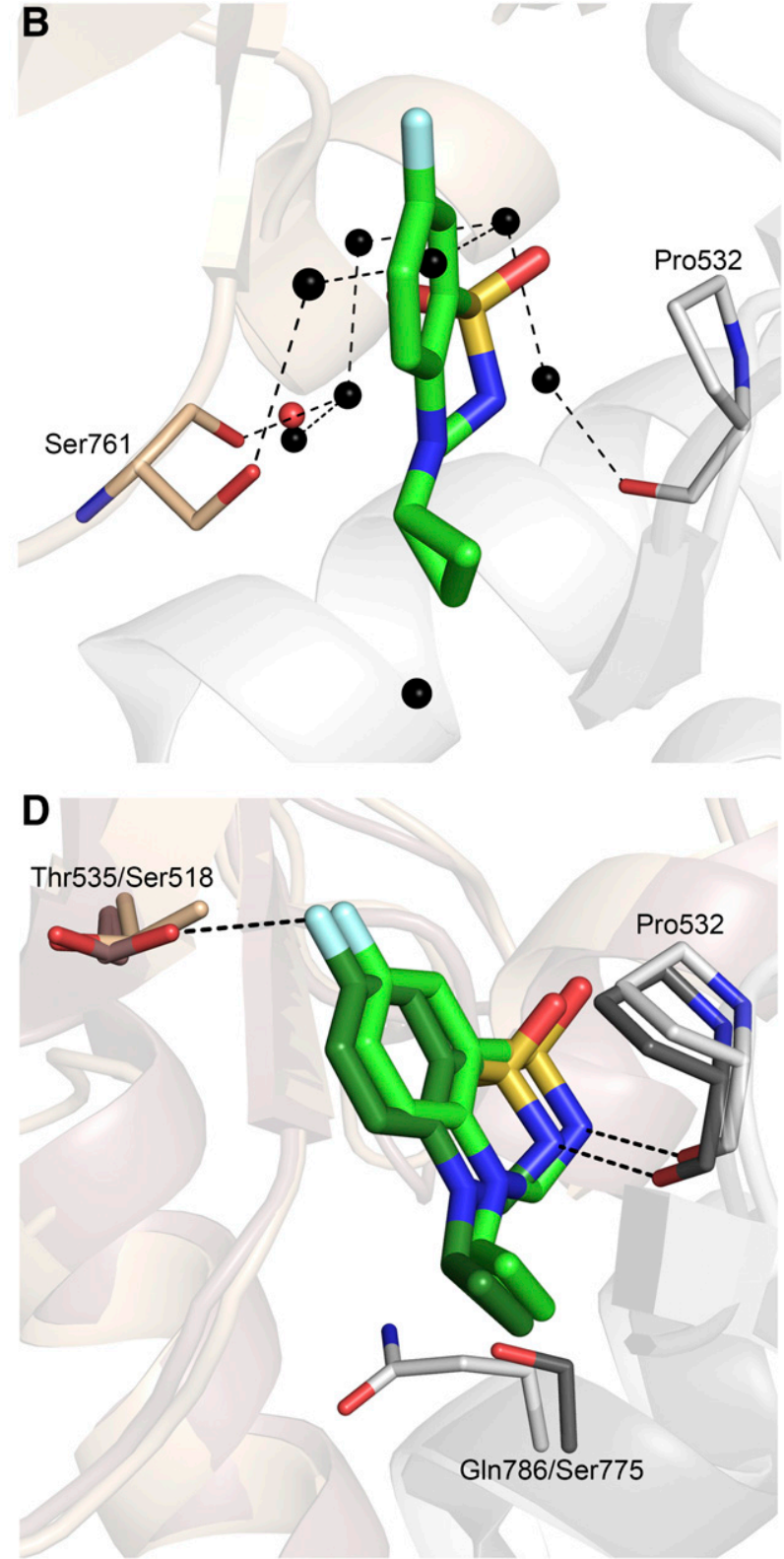

Fig. 7. Displacement of water molecules, specific side-chain comparisons, and chloride-binding site. (A) The location of the two BPAM344 molecules at the modulator-binding site in GluK1-LBD relative to the chloride ion-binding site (green sphere). (B) Displacement of water molecules by BPAM344 (green sticks) at the dimer interface. GluK1-LBD (Protein Data Bank identifier 4e0x) is shown with subunit A in beige and subunit B in gray, and water molecules are shown as black spheres. One conserved water molecule in the structure with BPAM344 is shown as a red sphere. (C) Comparison of the side-chain conformation of Thr535 with BPAM344 bound (GluK1 subunit colored beige, BPAM344 green) and BPAM521 bound (GluK1 subunit colored white, BPAM521 cyan). The hydrogen bond from the 7-hydroxyl group in BPAM521 to the side-chain hydroxyl group in Thr535 is shown as a stippled line. (D) Comparison of BPAM344 binding in GluK1-LBD and GluA2-LBD (Protein Data Bank identifier 4n07). The two residues located within 4 Å of the modulator are shown in stick representation. GluA2 is shown in dark salmon for subunit A and dark gray for subunit B. BPAM344 is shown in green in GluK1 and dark green in GluA2.

stability of the dimer interface in the active conformation. Stabilization of the dimer interface has previously been suggested to slow down desensitization of AMPARs (Sun et al., 2002; Jin et al., 2005) and KARs (Plested and Mayer, 2007; Veran et al., 2012). Consistent with a role of BPAM344 and BPAM521 in stabilizing the dimer interface, these compounds strongly reduce desensitization of GluK1, GluK2a, and GluK3a.

In contrast, only a limited effect on deactivation kinetics was observed (Figs. $2 \mathrm{~F}$ and $4 \mathrm{G}$ ). The domain closure of GluK1LBD in complex with kainate and BPAM344 $\left(26^{\circ}\right.$ in both subunits) is similar to that of GluK1-LBD structures with kainate alone (25-28 ${ }^{\circ}$ ) (Møllerud et al., 2017). Binding of BPAM521 and BPAM121 also does not lead to significant changes in domain closure (26 in subunit A and $27^{\circ}$ in B). Thus, D1-D2 hinge region movements and agonist binding do not seem to be affected upon binding of small molecules at the modulator-binding site in GluK1.

Similar to BPAM344, BPAM521 contains a cyclopropyl group in the 4-position of the BTD scaffold, whereas the 7-fluorine atom in BPAM344 is replaced by a hydroxyl substituent. This allowed us to investigate the role of a strong 
hydrogen bond acceptor in the modulator. Substituting the 7-fluorine atom of BPAM344 with the hydroxyl group in BPAM521 was shown to significantly decrease potency and desensitization decay time (Figs. 2 and 4). Comparing GluK1LBD in complex with BPAM344 and BPAM521, respectively, one major difference is found in the modulator-binding site with respect to the Thr535 side-chain conformation (Fig. 7C). With BPAM344 bound, Thr535 adopts a conformation where the side-chain methyl and hydroxyl groups point away from the 7-fluorine atom of BPAM344. In contrast, flexibility is seen in the Thr535 side chain when BPAM521 is bound. Thr535 adopts two different conformations, both having the hydroxyl group facing the binding site, which allows for the formation of a polar contact to the 7-hydroxy group of BPAM521. This suggests an important role of Thr535 in positive allosteric modulation of KARs.

The location and interactions of the modulators are similar to those seen in the structures of the AMPAR GluA2-LBD with BPAM344 (Nørholm et al., 2013) and BPAM521 (Krintel et al., 2016) (Fig. 7D). Within $4 \AA$ of the modulators, two residues differ between GluK1-3 and GluA1-2: Thr535 in KARs that correspond to Ser518 in AMPARs, and Gln786 in KARs that correspond to Ser775 in the AMPAR flip isoform or Asn775 in the flop isoform (Fig. 7D). The side chain of Gln786 in GluK1 points away from the modulator-binding site, and therefore does not have close contact with the modulators. Thr535 could adopt several conformations in each subunit of GluK1-LBD with kainate (Plested et al., 2008; Venskutonytè et al., 2012), whereas we observed a single conformation when BPAM344 was bound. This suggests that the 7-fluorine atom locks Thr535 in a position pointing away from the modulator, thereby forming a steric interaction only $(\sim 3.5 \AA$ between 7-fluorine atom of BPAM344 and the Thr535 $\mathrm{C} \gamma 2$ atom). A similar conformation of Thr535 is observed with BPAM121 bound to avoid steric clash between the 7-chlorine atom of BPAM121 and the side chain of Thr535 ( $23.4 \AA$ between 7-chlorine atom of BPAM121 and the Thr535 $\mathrm{C} \gamma 2$ atom). These close contacts, combined with no significant potency of BPAM121 at GluK2a, suggest that a small substituent, e.g., fluorine, in the 7-position of the BTD scaffold is required for a modulatory effect when targeting KARs. The conformational restriction of Thr535 in GluK1 in the presence of the modulator most likely results in an entropic penalty, partly explaining the 90-fold lower potency of BPAM344 at GluK2a compared with AMPARs $\left(\mathrm{EC}_{50}\right.$ of $\left.0.9 \mu \mathrm{M}\right)(\mathrm{N} ø$ rholm et al., 2013).

Two cations and one anion are critical for proper functioning of KARs (Paternain et al., 2003; Plested and Mayer, 2007; Plested et al., 2008; Chaudhry et al., 2009; Bowie, 2010). In the GluK1-LBD structures, the chloride ion is still present, being located $7.2 \AA$ from the sulfonamide O atom of BPAM344 (Fig. 7A), whereas no cations could confidently be modeled in the cation-binding sites. The two modulator-binding sites are separated from the anion-binding site by Lys531 from each subunit of the dimer. This shows that the two modulatory sites and the anion-binding site can be occupied simultaneously, and suggests that the modulator-binding sites do not interfere with the ion-binding sites.

In conclusion, we have characterized promising positive allosteric modulators of KARs capable of increasing glutamate-evoked currents 21-fold at GluK2a and 59-fold at GluK3a. Despite the mid-micromolar range potency of the modulator, BPAM344 may prove a useful pharmacological tool, e.g., to slow the entry into the desensitized state of fast desensitizing KARs for identification of orthosteric ligands (e.g., agonists or partial agonists) as well as functional studies in vivo. However, it remains to be determined whether these compounds are also effective on native KARs, keeping in mind that the major population of KARs in the brain are heteromers composed of GluK2 and GluK5. Our structure-function study should help in designing new compounds with high selectivity of kainate over AMPA receptors. KARs control the activity of neuronal circuits, in particular in the hippocampus (Carta et al., 2014), likely taking part in spatial memory and behavioral flexibility (Micheau et al., 2014). It will be interesting to test whether selective KAR-positive allosteric modulators may improve cognitive functions.

\section{Acknowledgments}

The authors thank MAX-Laboratory for providing beamtime.

\section{Authorship Contributions}

Participated in research design: Larsen, Fièvre, Frydenvang, Pirotte, Kastrup, Mulle.

Conducted experiments: Larsen, Frydenvang, Kastrup.

Contributed new reagents or analytic tools: Francotte, Pirotte.

Performed data analysis: Larsen, Fièvre, Frydenvang, Kastrup, Mulle.

Wrote or contributed to the writing of the manuscript: Larsen, Pirotte, Kastrup, Mulle.

\section{References}

Adams PD, Afonine PV, Bunkóczi G, Chen VB, Davis IW, Echols N, Headd JJ, Hung L-W, Kapral GJ, Grosse-Kunstleve RW, et al. (2010) PHENIX: a comprehensive Python-based system for macromolecular structure solution. Acta Crystallogr D Biol Crystallogr 66:213-221.

Armstrong N and Gouaux E (2000) Mechanisms for activation and antagonism of an AMPA-sensitive glutamate receptor: crystal structures of the GluR2 ligand binding core. Neuron 28:165-181.

Bowie D (2010) Ion-dependent gating of kainate receptors. J Physiol 588:67-81.

Bowie D, Garcia EP, Marshall J, Traynelis SF, and Lange GD (2003) Allosteric regulation and spatial distribution of kainate receptors bound to ancillary proteins. $J$ Physiol 547:373-385.

Carta M, Fièvre S, Gorlewicz A, and Mulle C (2014) Kainate receptors in the hippocampus. Eur J Neurosci 39:1835-1844.

Chaudhry C, Weston MC, Schuck P, Rosenmund C, and Mayer ML (2009) Stability of ligand-binding domain dimer assembly controls kainate receptor desensitization. EMBO J 28:1518-1530.

Chen VB, Arendall III WB, Headd JJ, Keedy DA, Immormino RM, Kapral GJ, Murray LW, Richardson JS, and Richardson DC (2010) MolProbity: all-atom structure validation for macromolecular crystallography. Acta Crystallogr Sect D 66:12-21.

Emsley P, Lohkamp B, Scott WG, and Cowtan K (2010) Features and development of Coot. Acta Crystallogr D Biol Crystallogr 66:486-501.

Evans P (2006) Scaling and assessment of data quality. Acta Crystallogr D Biol Crystallogr 62:72-82.

Everts I, Petroski R, Kizelsztein P, Teichberg VI, Heinemann SF, and Hollmann M (1999) Lectin-induced inhibition of desensitization of the kainate receptor GluR6 depends on the activation state and can be mediated by a single native or ectopic N-linked carbohydrate side chain. J Neurosci 19:916-927.

Francotte $\mathrm{P}$, de Tullio $\mathrm{P}$, Podona $\mathrm{T}$, Diouf $\mathrm{O}$, Fraikin $\mathrm{P}$, Lestage $\mathrm{P}$, Danober $\mathrm{L}$ Thomas J-Y, Caignard D-H, and Pirotte B (2008) Synthesis and pharmacological evaluation of a second generation of pyridothiadiazine 1,1-dioxides acting as AMPA potentiators. Bioorg Med Chem 16:9948-9956.

Francotte P, Goffin E, Fraikin P, Graindorge E, Lestage P, Danober L, Challal S, Rogez N, Nosjean O, Caignard D-H, et al. (2013) Development of thiophenic analogues of benzothiadiazine dioxides as new powerful potentiators of 2-amino-3-(3hydroxy-5-methylisoxazol-4-yl)propionic acid (AMPA) receptors. J Med Chem 56: $7838-7850$.

Francotte P, Goffin E, Fraikin P, Lestage P, Van Heugen J-C, Gillotin F, Danober L, Thomas J-Y, Chiap P, Caignard D-H, et al. (2010) New fluorinated 1,2,4-benzothiadiazine 1,1-dioxides: discovery of an orally active cognitive enhancer acting through potentiation of the 2-amino-3-(3-hydroxy-5-methylisoxazol-4-yl)propionic acid receptors. J Med Chem 53:1700-1711.

Francotte P, Nørholm A-B, Deva T, Olsen L, Frydenvang K, Goffin E, Fraikin P, de Tullio P, Challal S, Thomas J-Y, et al. (2014) Positive allosteric modulators of 2-amino-3-(3-hydroxy-5-methylisoxazol-4-yl)propionic acid receptors belonging to 4-cyclopropyl-3,4-dihydro-2h-1,2,4-pyridothiadiazine dioxides and diversely chlorosubstituted 4-cyclopropyl-3,4-dihydro-2H-1,2,4-benzothiadiazine 1,1-dioxides. $J$ Med Chem 57:9539-9553. 
Francotte P, Tullio Pd, Goffin E, Dintilhac G, Graindorge E, Fraikin P, Lestage P, Danober L, Thomas J-Y, Caignard D-H, et al. (2007) Design, synthesis, and pharmacology of novel 7-substituted 3,4-dihydro-2H-1,2,4-benzothiadiazine 1,1dioxides as positive allosteric modulators of AMPA receptors. J Med Chem 50: 3153-3157.

Galano A, Alvarez-Idaboy JR, and Vivier-Bunge A (2007) Non-alkane behavior of cyclopropane and its derivatives: characterization of unconventional hydrogen bond interactions. Theor Chem Acc 118:597-606.

Hayward S and Berendsen HJ (1998) Systematic analysis of domain motions in proteins from conformational change: new results on citrate synthase and T4 lysozyme. Proteins 30:144-154.

Huettner JE (1990) Glutamate receptor channels in rat DRG neurons: activation by kainate and quisqualate and blockade of desensitization by Con A. Neuron 5 $255-266$.

Jane DE, Lodge D, and Collingridge GL (2009) Kainate receptors: pharmacology, function and therapeutic potential. Neuropharmacology 56:90-113.

Jin R, Clark S, Weeks AM, Dudman JT, Gouaux E, and Partin KM (2005) Mechanism of positive allosteric modulators acting on AMPA receptors. J Neurosci 25 9027-9036.

Kabsch W (2010) XDS. Acta Crystallogr D Biol Crystallogr 66:125-132 International Union of Crystallography.

Krintel C, Francotte P, Pickering DS, Juknaite L, Pøhlsgaard J, Olsen L, Frydenvang K, Goffin E, Pirotte B, and Kastrup JS (2016) Enthalpy-Entropy Compensation in the Binding of Modulators at Ionotropic Glutamate Receptor GluA2. Biophys $J$ 110:2397-2406.

Krintel C, Frydenvang K, Olsen L, Kristensen MT, de Barrios O, Naur P, Francotte P, Pirotte B, Gajhede M, and Kastrup JS (2012) Thermodynamics and structural analysis of positive allosteric modulation of the ionotropic glutamate receptor GluA2. Biochem $J$ 441:173-178.

Larsen AP, Francotte P, Frydenvang K, Tapken D, Goffin E, Fraikin P, Caignard D-H Lestage P, Danober L, Pirotte B, et al. (2016) Synthesis and Pharmacology of Mono-, Di-, and Trialkyl-Substituted 7-Chloro-3,4-dihydro-2H-1,2,4-benzothiadiazine 1,1-Dioxides Combined with X-ray Structure Analysis to Understand the Unexpected Structure-Activity Relationship at AMPA Receptors. ACS Chem Neurosci 7:378-390.

Lerma J and Marques JM (2013) Kainate receptors in health and disease. Neuron 80: 292-311.

McCoy AJ, Grosse-Kunstleve RW, Adams PD, Winn MD, Storoni LC, and Read RJ (2007) Phaser crystallographic software. J Appl Cryst 40:658-674.

Micheau J, Vimeney A, Normand E, Mulle C, and Riedel G (2014) Impaired hippocampus-dependent spatial flexibility and sociability represent autism-like phenotypes in GluK2 mice. Hippocampus 24:1059-1069.

Møllerud S, Frydenvang K, Pickering DS, and Kastrup JS (2017) Lessons from crystal structures of kainate receptors. Neuropharmacology 112 (Pt A): $16-28$

Moriarty NW, Grosse-Kunstleve RW, and Adams PD (2009) electronic Ligand Builder and Optimization Workbench (eLBOW): a tool for ligand coordinate and restraint generation. Acta Crystallogr D Biol Crystallogr 65:1074-1080.

Naur P, Vestergaard B, Skov LK, Egebjerg J, Gajhede M, and Kastrup JS (2005) Crystal structure of the kainate receptor GluR5 ligand-binding core in complex with (S)-glutamate. FEBS Lett 579:1154-1160.

Nørholm A-B, Francotte P, Goffin E, Botez I, Danober L, Lestage P, Pirotte B, Kastrup JS, Olsen L, and Oostenbrink C (2014) Thermodynamic characterization of new positive allosteric modulators binding to the glutamate receptor A2 ligand-binding domain: combining experimental and computational methods unravels differences in driving forces. $J$ Chem Inf Model 54: 3404-3416.

Nørholm A-B, Francotte P, Olsen L, Krintel C, Frydenvang K, Goffin E, Challal S, Danober L, Botez-Pop I, Lestage P, et al. (2013) Synthesis, pharmacological and structural characterization, and thermodynamic aspects of GluA2-positive allosteric modulators with a 3,4-dihydro-2H-1,2,4-benzothiadiazine 1,1-dioxide scaffold. J Med Chem 56:8736-8745.

Partin KM, Patneau DK, Winters CA, Mayer ML, and Buonanno A (1993) Selective modulation of desensitization at AMPA versus kainate receptors by cyclothiazide and concanavalin A. Neuron 11:1069-1082.

Paternain AV, Cohen A, Stern-Bach Y, and Lerma J (2003) A role for extracellular $\mathrm{Na}+$ in the channel gating of native and recombinant kainate receptors. J Neurosci 23:8641-8648.

Perrais D, Coussen F, and Mulle C (2009) Atypical functional properties of GluK3containing kainate receptors. J Neurosci 29:15499-15510.

Perrais D, Veran J, and Mulle C (2010) Gating and permeation of kainate receptors: differences unveiled. Trends Pharmacol Sci 31:516-522.

Pinheiro P and Mulle C (2006) Kainate receptors. Cell Tissue Res 326:457-482.

Plested AJR and Mayer ML (2007) Structure and mechanism of kainate receptor modulation by anions. Neuron 53:829-841.

Plested AJR, Vijayan R, Biggin PC, and Mayer ML (2008) Molecular basis of kainate receptor modulation by sodium. Neuron 58:720-735.

Pøhlsgaard J, Frydenvang K, Madsen U, and Kastrup JS (2011) Lessons from more than 80 structures of the GluA2 ligand-binding domain in complex with agonists, antagonists and allosteric modulators. Neuropharmacology 60:135-150.

Schiffer HH, Swanson GT, and Heinemann SF (1997) Rat GluR7 and a carboxyterminal splice variant, GluR7b, are functional kainate receptor subunits with a low sensitivity to glutamate. Neuron 19:1141-1146.

Sobolevsky AI, Rosconi MP, and Gouaux E (2009) X-ray structure, symmetry and mechanism of an AMPA-subtype glutamate receptor. Nature 462:745-756.

Sun Y, Olson R, Horning M, Armstrong N, Mayer M, and Gouaux E (2002) Mechanism of glutamate receptor desensitization. Nature 417:245-253.

Terwilliger TC, Grosse-Kunstleve RW, Afonine PV, Moriarty NW, Zwart PH, Hung L-W, Read RJ, and Adams PD (2008) Iterative model building, structure refinement and density modification with the PHENIX AutoBuild wizard. Acta Crystallogr D Biol Crystallogr 64:61-69.

Ursby T, Unge J, Appio R, Logan DT, Fredslund F, Svensson C, Larsson K, Labrador A, and Thunnissen MMGM (2013) The macromolecular crystallography beamline I911-3 at the MAX IV laboratory. $J$ Synchrotron Radiat 20:648-653.

Venskutonyte R, Frydenvang K, Gajhede M, Bunch L, Pickering DS, and Kastrup JS (2011) Binding site and interlobe interactions of the ionotropic glutamate receptor GluK3 ligand binding domain revealed by high resolution crystal structure in complex with (S)-glutamate. J Struct Biol 176:307-314.

Venskutonyte R, Frydenvang K, Hald H, Rabassa AC, Gajhede M, Ahring PK, and Kastrup JS (2012) Kainate induces various domain closures in AMPA and kainate receptors. Neurochem Int 61:536-545.

Veran J, Kumar J, Pinheiro PS, Athané A, Mayer ML, Perrais D, and Mulle C (2012) Zinc potentiates GluK3 glutamate receptor function by stabilizing the ligand binding domain dimer interface. Neuron 76:565-578.

Winn MD, Ballard CC, Cowtan KD, Dodson EJ, Emsley P, Evans PR, Keegan RM, Krissinel EB, Leslie AGW, and McCoy A et al. (2011) Overview of the CCP4 suite and current developments. Acta Cryst 67:235-242.

Zhu S and Gouaux E (2017) Structure and symmetry inform gating principles of ionotropic glutamate receptors. Neuropharmacology 112 (Pt A):11-15.

Address correspondence to: Christophe Mulle, Interdisciplinary Institute for Neuroscience, University of Bordeaux, Centre National de la Recherche Scientifique, Unité Mixte de Recherche 5297, F-33000 Bordeaux, France. E-mail: christophe.mulle@u-bordeaux.fr or Jette Sandholm Kastrup, Biostructural Research, Department of Drug Design and Pharmacology, Faculty of Health and Medical Sciences, University of Copenhagen, Jagtvej 162, DK-2100 Copenhagen, Denmark. E-mail: jsk@sund.ku.dk 